\title{
Factors affecting mortality of critical care trauma patients
}

\author{
Hefny $\mathrm{AF}^{1}$, Idris $\mathrm{K}^{2}$, Eid $\mathrm{HO}^{1}$, *Abu-Zidan $\mathrm{FM}^{1}$
}

1. Trauma Group, Department of Surgery, Faculty of Medicine and Health Sciences, UAE University, AlAin, United Arab Emirates

2. Intensive Care Unit, Al-Ain Hospital, Al-Ain, United Arab Emirates

\begin{abstract}
Background: Critically-ill trauma patients have a high mortality. Emirates (UAE). AIS for the chest and head injuries and the ISS were studied. mortality was 13.5 .

\section{Introduction}

About 5.8 million people die each year as a result of injuries. This accounts for $10 \%$ of the world's deaths. ${ }^{1}$ Trauma is a major health problem in the United Arab Emirates (UAE) and it is the second leading cause of death. ${ }^{2}$ Critically-ill patients are usually treated in the Intensive Care Units (ICU) where the hospital highest mortality rates occur. ${ }^{3}$ Early identification and management of patients having the highest risk of death may contribute to better understanding of these injuries and their outcome. Our aim was to study the factors affecting mortality of trauma patients treated in a general ICU at Al-Ain Hospital, UAE.
\end{abstract}

Objective: To study the factors affecting the mortality of ICU trauma patients treated at Al-Ain Hospital, United Arab

Methods: All trauma patients who were admitted to the ICU were prospectively collected over three years (2003-2006). Univariate and multivariate analysis were used to compare patients who died and who did not. Gender, age, nationality, mechanism of injury, systolic blood pressure and GCS on arrival, the need for ventilation, presence of head or chest injuries,

Results: There were 202 patients (181 males). The most common mechanism of injury was road traffic collisions (72.3\%). The overall mortality was $13.9 \%$. A direct logistic regression model has shown that factors that affected mortality were decreased GCS $(p<0.0001)$, mechanism of injury $(p=0.004)$ with burns having the highest mortality, increased age $(p=$ $0.004)$, and increased ISS $(p=0.02)$. The best GCS that predicted mortality was 5.5 while the best ISS that predicted

Conclusion: Road traffic collision is the most common cause of serious trauma in UAE followed by falls. Decreased GCS was the most significant factor that predicted mortality in the ICU trauma patients.

Key words: Intensive Care Unit, injury, epidemiology, hospitalization, registry, mortality

African Health Sciences 2013; 13(3): 731 - 735 http://dx.doi.org/10.4314/ahs.v13i3.30

\begin{tabular}{|l|}
\hline *Corresponding author: \\
Fikri Abu-Zidan \\
Professor, Head, Trauma Group, Trauma and \\
Acute Care Surgeon \\
Department of Surgery \\
Faculty of Medicine and Health Sciences \\
P O Box 17666, Al-Ain, United Arab Emirates \\
Tel: (+971) 37137579 \\
E-mail: fabuzidan@uaeu.ac.ae \\
\hline
\end{tabular}

African Health Sciences Vol 13 Issue 3 September 2013

\section{Methods}

All trauma patients who were admitted to the ICU of Al-Ain Hospital were studied. Data for patients were retrieved from Al-Ain Hospital Trauma Registry which were prospectively collected over three years (2003-2006).

Al-Ain Hospital is a 400-bed teaching hospital and one of the two major hospitals in AlAin city, the largest city in the eastern district of Abu Dhabi, with 463000 inhabitants. ${ }^{4}$ During the study period, the ICU of Al-Ain Hospital was an open 8 bed ICU. The admitting consultant, who was a surgeon or a physician, was in charge of the criticallyill patient who was managed in collaboration with the critical care physician. The nurse to patient ratio was 1:2. There were no regular daily ICU clinical rounds. During on call, the consultant was available on demand. There were no ICU protocols or management guidelines. The hospital had no separate Neuro-ICU. The average number of total ICU admissions was about 350 patients per year and about $20 \%$ of them were trauma patients. Al-Ain Hospital treated almost $80 \%$ of all hospitalized trauma patients in our city during the study period.

The Local Ethics Committee of Al-Ain Health District Area has approved data collection 
for all trauma patients who were admitted to AlAin Hospital or who have died in the Emergency Department (Ethical approval NO: RECA/02/44).

Demography of patients including gender, age and nationality, mechanism of injury, heart rate, systolic blood pressure and Glasgow Coma Scale (GCS) on arrival, the need for mechanical ventilation, Injury Severity Score (ISS), presence of head or chest injuries, Abbreviate Injury Score (AIS) for the chest and head, hospital stay, and mortality were analyzed.

\section{Statistical analysis}

We used Fisher's exact test to compare categorical data of two independent groups and Mann-Whitney U-test to compare continuous or ordinal data of two independent groups. Univariate analysis was used to compare patients who survived and those who died. Significant factors were then entered into a direct logistic regression model. A p value of $<0.05$ was considered significant. Data were analyzed with PASW Statistics 18, SPSS Inc, USA. Percentages of population by nationality and gender were retrieved from the United Arab Emirates Census. ${ }^{5}$

\section{Results}

There were 202 trauma patients treated at the ICU, 181(90\%) were males. Median (range) age was 30 (1-80) years. 46 patients $(23.2 \%)$ were UAE nationals. The most common mechanism of injury was road traffic collisions (RTC) $(72.3 \%)$ followed by falls $(15.9 \%)$ and burns $(5.4 \%)$ (table 1$)$.

Table 1: ICU trauma patients by mechanism, Al-Ain, United Arab Emirates 2003-2006 (n = 202)

\begin{tabular}{ll}
\hline Mechanism of trauma & Number (\%) \\
\hline Road traffic collisions & $146(72.3)$ \\
Fall & $32(15.9)$ \\
From height & $29(14.4)$ \\
From same level & $3(1.5)$ \\
Burn & $11(5.4)$ \\
Others & $13(6.4)$ \\
Total & $202(100)$ \\
\hline
\end{tabular}

$147(72.8 \%)$ patients arrived at hospital by ambulance and $49(24.3 \%)$ by private vehicles. The median (range) ISS was 17 (1-41). The median (range) GCS was 13 (3-15). The mean (SD) ICU length of stay was 5.7 (6.7) days while the mean (SD) hospital stay was 17.7 (22) days. 28 patients died in the ICU (overall mortality of $13.9 \%$ ).

Univariate analysis has shown significant difference between patients who survived and those who died with regard to increased age $(\mathrm{p}=0.016)$, decreased GCS ( $p=0.001)$, increased ISS ( $p<0.0001)$, mechanism of trauma $(p=0.004)$ with burns having the highest mortality, and the need for mechanical ventilation $(p=0.001)$ (table 2$)$.

When the significant factors were entered into a direct logistic regression model, this model has shown that independent factors that affected mortality were decreased GCS ( $p<0.0001)$, mechanism of injury $(p=0.004)$, increased age $(p=0.004)$, and increased ISS $(p=0.02)$ (table 3$)$. Burns had the highest mortality in the ICU ( $p=0.03)$ compared with other mechanisms. The Receiver Operating Characteristic (ROC) curve for the best GCS that predicted mortality was 5.5 (figure 1) while the best ISS that predicted mortality was 13.5 (figure 2).

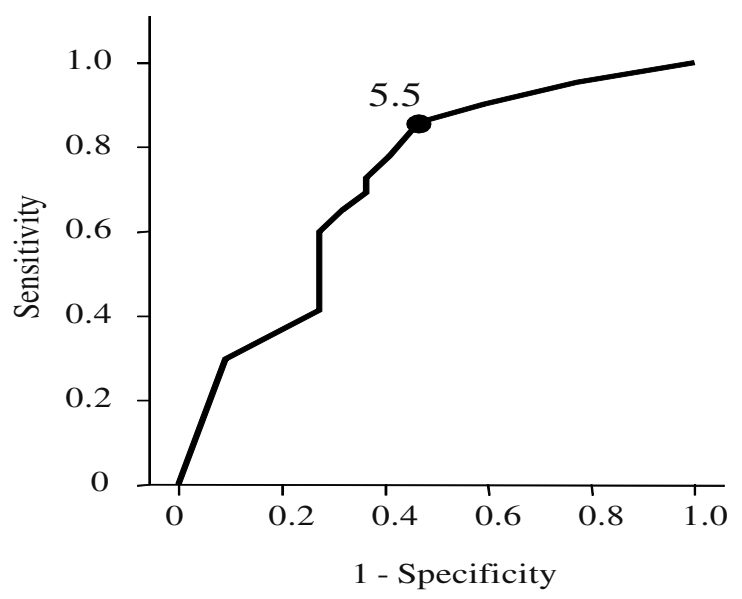

Figure 1: Receiver Operating Characteristic (ROC) curve for the best GCS that predicted mortality in ICU trauma patients, Al-Ain Hospital, Al-Ain, United Arab Emirates 20032006 
Table 2: Univariate analysis comparing ICU trauma patients who died $(\mathrm{n}=28)$ and survived $(\mathrm{n}=$ 174), Al-Ain, United Arab Emirates, 2003-2006

\begin{tabular}{|c|c|c|c|}
\hline Variable & $\begin{array}{l}\text { Survived } \\
(\%) \mathrm{n}=174\end{array}$ & $\begin{array}{l}\text { Non-survivor } \\
(\%) \mathrm{n}=28\end{array}$ & $\mathrm{p}$ value \\
\hline Median age years (range) & $29(1-80)$ & $35(4-65)$ & 0.016 \\
\hline Gender & & & 0.58 \\
\hline Male & $156(89.7)$ & $25(89.3)$ & \\
\hline Female & $18(10.3)$ & $3(10.7)$ & \\
\hline Nationality ${ }^{a}$ & & & 0.2 \\
\hline UAE & $42(24.6)$ & $4(14.8)$ & \\
\hline Non UAE & $129(75.4)$ & $23(85.2)$ & \\
\hline Median (range) heart rate per minute & $97(50-180)$ & $91(60-180)$ & 0.71 \\
\hline $\begin{array}{l}\text { Median Systolic blood pressure } \mathrm{mmHg} \\
\text { (range) }\end{array}$ & g130 (78-224) & $120(50-215)$ & 0.25 \\
\hline GCS median (range) & $13(3-15)$ & $5(3-15)$ & 0.001 \\
\hline ISS median (range) & $17(1-41)$ & $25(4-36)$ & $<0.0001$ \\
\hline AIS head median (range) & $2(0-4)$ & $3(0-5)$ & 0.3 \\
\hline AIS chest median (range) & $0(0-4)$ & $0(0-3)$ & 0.76 \\
\hline Mechanism & & & 0.004 \\
\hline Road traffic collision & $127(73)$ & $19(67.8)$ & \\
\hline Fall & $30(17.2)$ & $2(7.1)$ & \\
\hline Burn & $5(2.9)$ & $6(21.4)$ & \\
\hline Others & $12(6.9)$ & $1(3.6)$ & \\
\hline Ventilated & $77(44.3)$ & $22(78.6)$ & 0.001 \\
\hline Head injury & $107(61.5)$ & $18(64.3)$ & 0.83 \\
\hline Chest injury & $77(44.3)$ & $11(39.3)$ & 0.68 \\
\hline
\end{tabular}

Table 3: Direct logistic regression model defining factors affecting ICU mortality

\begin{tabular}{llllll}
\hline Variable & Estimate & SE & Walld test & p Value & Odds ratio \\
\hline GCS & -0.36 & 0.09 & 14.45 & $<0.0001$ & 0.7 \\
Mechanism* & & & 13.52 & 0.004 & \\
Road traffic collision & -0.38 & 1.22 & 0.1 & 0.753 & 0.68 \\
Falls & -2.44 & 1.73 & 2 & 0.157 & 0.09 \\
Burn & 3.11 & 1.44 & 4.65 & 0.03 & 22.47 \\
Age & 0.07 & 0.02 & 8.46 & 0.004 & 1.07 \\
ISS & 0.08 & 0.03 & 5.392 & 0.02 & 1.08 \\
Ventilation & 0.23 & 0.66 & 0.12 & 0.73 & 1.26
\end{tabular}

*Reference is (others) mechanism of injury

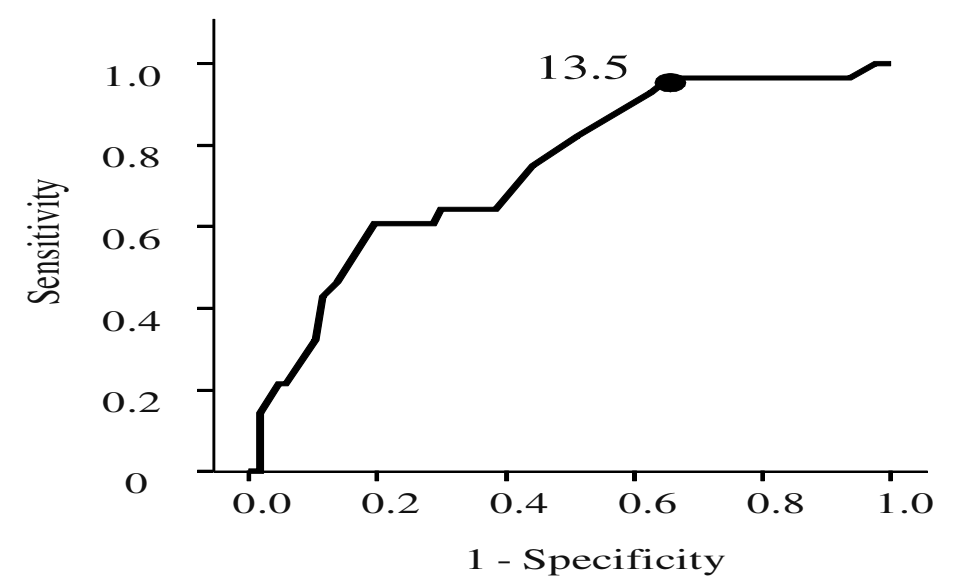

Figure 2: Receiver Operating Characteristic (ROC) curve for the best ISS that predicted mortality in ICU trauma patients, Al-Ain Hospital, Al-Ain, United Arab Emirates 2003-2006 


\section{Discussion}

ICU trauma patients have usually severe injuries and high mortality. The majority of ICU trauma patients in our study were males and the gender did not affect the mortality. This is similar to other studies. ${ }^{6,7}$ The percentage of UAE nationals of the ICU trauma patients is similar to their percentage in our community. ${ }^{4}$

Trauma patients are usually young. ${ }^{8}$ The median age of the patients in our study is less than that reported in other studies. ${ }^{9}$ This may be due to the fact that more than $90 \%$ of the population in UAE is less than 50 years of age. ${ }^{5}$ About $5 \%$ of all trauma patients who are admitted to our hospital are older than 60 years. ${ }^{10}$ Our study has shown that increased age was an independent risk factor for increased mortality. This can be attributed to reduced physiological reserve by increased age as have been shown by others. ${ }^{11,12}$

RTC is a major health problem worldwide. RTC mortality in the UAE has been estimated to be 37 per 100000 population per year, one of the highest in the world. ${ }^{13}$ Similar to other studies, we have shown that RTC was the most common mechanism of injury in trauma patients admitted to the ICU. ${ }^{6,11}$ Falls were the second most common cause of ICU admission. We have shown that occupational injuries cause about $30 \%$ of hospitalization of trauma patients in our hospital. Majority of these injuries are caused by fall from height. ${ }^{14}$ Preventive measures that increase work place safety is important to avoid such injuries. Furthermore, our study has shown that the mortality rate among burn patients was significantly higher than other mechanisms of injury. This is due to the fact that only serious burns with higher percentage of burned total body surface area are admitted to our ICU. ${ }^{15}$ Burns are associated with a higher risk of sepsis which is the main cause of morbidity and mortality in the ICU. ${ }^{16}$

ISS was significantly higher in those who died. The high ISS in our study indicates severe injury of admitted patients. Similar to other studies, ISS was an independent risk factor for mortality. ${ }^{17}$ The best ISS that predicts mortality in our study was 13.5. Some studies have shown that ISS was not an independent risk factor for mortality. ${ }^{6,11,18}$ It is possible that including only very severely injured patients in these studies (median ISS e" 24) reduced the ability of the logistic regression model to detect these factors.
Mechanical ventilation is one of the main reasons to admit patients to the ICU. Although, there was a significant increase in the need for mechanical ventilation for non-survivors in the univariate analysis, it was not an independent factor in predicting mortality in the multivariate analysis model. This is possibly because it was correlated to reduced GCS and high ISS. Other studies have shown that the duration of mechanical ventilation is a risk factor for mortality in trauma patients. ${ }^{19}$

The overall ICU mortality in our study is similar to other studies. ${ }^{11,20}$ Injury to the central nervous system is the leading cause of mortality in trauma patients. ${ }^{16}$ More than $60 \%$ of our trauma patients who died had head injury. This can be explained by the low compliance of seatbelts in our community which is as low as $11 \%$ leading to more head injury. ${ }^{14}$ Seatbelts will restrain the body of the vehicle's occupant to the seat and prevent the head from hitting the windscreen in deceleration injuries. Patients who survived in our study have a significantly higher GCS compared to non-survivors. Similar to other studies, GCS was an independent risk factor that predicts mortality in the ICU trauma patients. ${ }^{6}, 11$ The best GCS that could predict mortality in our study was 5.5 .

\section{Limitations of the study}

Our study period was about 7 years ago which raises the question whether its findings reflect what happens at the present time. There have been major changes in our ICU in the last 3 years. The ICU became a general closed ICU having 14 beds. The ICU physician became in charge of the management of all admitted critically-ill patients. Regular daily ICU clinical meeting, rounds, and handover were established. 24 hour consultant coverage has been achieved and ICU protocols and management guidelines were developed. The nurse to patient ratio increased to 1:1.5. Despite these developments, the ICU mortality of trauma patients in the last three years did not differ from the present study (19/170 (11.2\%) compared with 28/202 (13.9\%), p $=0.44$, Chi Square test). The observed severity of head injury in our setting is still high because of a very low compliance of seatbelt usage. ${ }^{21}$ Critical care will not be able to improve the outcome of primary severe head injury. Furthermore, there is a national demand for intensive care beds in Al-Ain City. Sometimes trauma patients are treated in the Emergency Department or Post-anaesthesia Care Unit in the operating theatre until a bed becomes available in the ICU. Occasionally elective major surgery is cancelled due to shortage of ICU beds.

We retrieved data from the Trauma Registry. This did not include APACHE or MODS scores which would have been helpful to understand how sick our patients were. The ISS is an anatomical severity score which does 
not adjust for ICU illnesses like ventilation acquired pneumonia, or adult respiratory distress syndrome.

\section{Conclusions}

Road traffic collision is the most common cause of serious trauma in UAE followed by falls. The majority of trauma patients who were admitted to the ICU had head injury. GCS was the most significant factor that predicted mortality in the ICU trauma patients in our setting.

\section{Acknowledgments}

This study was supported by Individual University Grant (\# 01-07-8-11/03), Faculty of Medicine Research Grants (NP/03/11,2003; and NP/04/28, 2004) and an Interdisciplinary Grant (\#02-07-8-1/4).

\section{References}

1. World Health Organization, Violence and injuries: the facts (2010). Website: http://whqlibdoc.who.int/ publications / 2010/9789241599375_eng.pdf [Accessed on 22 July 2010].

2. Fikri M, Noor A M, Shaheen H. Preventive Medicine Department 2002 Annual Report. Ministry of Health, Abu-Dhabi, UAE.

3. Colpan A, Akinci E, Erbay A, Balaban N, Bodur H. Evaluation of risk factors for mortality in intensive care units: a prospective study from a referral hospital in Turkey. Am J Infect Control 2005; 33:42-47.

4. Ministry of Health, Preventive Medicine Sector, United Arab Emirates, Annual report 2006. published on November 2007.

5. United Arab Emirates Census. Population Preliminary results 2005 by age and nationality. Adapted from: Preliminary Results of the General Census for Population, Housing and Establishments, 2005, United Arab Emirates. Available at: http:// www.zu.ac.ae/library/html/UAEInfo/documents/ CensusResults2005.pdf [Accessed May 27, 2010].

6. Brattström O, Granath F, Rossi P, Oldner A. Early predictors of morbidity and mortality in trauma patients treated in the intensive care unit. Acta Anaesthesiol Scand. 2010; 54:1007-1017

7. Gannon CJ, Napolitano LM, Pasquale M, Tracy JK, McCarter RJ. A statewide population-based study of gender differences in trauma: validation of a prior single-institution study. J Am Coll Surg 2002; 195:1118.

8. Korosec Jagodic H, Jagodic K, Podbregar M. Longterm outcome and quality of life of patients treated in surgical intensive care: a comparison between sepsis and trauma. Crit Care 2006; 10:R134.

9. Laudi S, Donaubauer B, Busch T, Kerner T, Bercker S, Bail H, Feldheiser A, Haas N, Kaisers U. Low incidence of multiple organ failure after major trauma. Injury 2007; 38:1052-1058.
10. Adam SH, Eid HO, Barss P, Lunsjo K, Grivna M, Torab FC, Abu-Zidan FM. Epidemiology of geriatric trauma in United Arab Emirates. Arch Gerontol Geriatr 2008; 47:377-382.

11. Ulvik A, Wentzel-Larsen T, Flaatten H. Trauma patients in the intensive care unit: short- and longterm survival and predictors of 30-day mortality. Acta Anaesthesiol Scand 2007; 51:171-177.

12. Taylor MD, Tracy JK, Meyer W, Pasquale M, Napolitano LM. Trauma in the elderly: intensive care unit resource use and outcome. J Trauma 2002; 53:407-414.

13. World Health Organization, Global status report on road safety: time for action. Geneva, 2009 Available at: htpp://www.who.int/violence_injury_prevention/ road_safety_status/2009 [Accessed on 9 August 2010].

14. Barss P, Addley K, Grivna M, Stanculescu C, AbuZidan F. Occupational injury in the United Arab Emirates: epidemiology and prevention. Occup Med (Lond) 2009; 59:493-498.

15. Pavoni V, Gianesello L, Paparella L, Buoninsegni LT, Barboni E. Outcome predictors and quality of life of severe burn patients admitted to intensive care unit. Scand J Trauma Resusc Emerg Med 2010; 18:24.

16. Thornhill R, Strong D, Vasanth S, Mackenzie I. Trauma Sepsis. Trauma 2010; 12: 31-49.

17. Ma YF, Sheng L, Gu J, Zhang M, Jiang GY. Analysis of clinical risk factors associated with mortality of severely injured multiple trauma patients with acute lung injury. Chin Med J (Engl) 2009; 122:701-705.

18. Navarrete-Navarro P, Ruiz-Bailén M, Rivera-Fernández R, Guerrero-López F, Pola-Gallego-de-Guzmán MD, Vázquez-Mata G. Acute respiratory distress syndrome in trauma patients: ICU mortality and prediction factors. Intensive Care Med 2000; 26:1624-1629.

19. Zhao XG, Wu JS, He XD, Ma YF, Zhang M, Gan JX, Xu SW, Jiang GY. Risk factors of mortality in road traffic injury patients with acute respiratory distress syndrome. Chin Med J (Engl) 2008; 121:968-972.

20. Vassar MJ, Lewis FR Jr, Chambers JA, Mullins RJ, O'Brien PE, Weigelt JA, et al. Prediction of outcome in intensive care unit trauma patients: a multicenter study of Acute Physiology and Chronic Health Evaluation (APACHE), Trauma and Injury Severity Score (TRISS), and a 24-hour intensive care unit (ICU) point system. J Trauma 1999; 47:324-329.

21. Abu-Zidan FM, Abbas AK, Hefny AF, Eid HO, Grivna M. Effects of seat belt usage on injury pattern and outome of vehicle occupants after road traffic collisions: prospective study. World J Surg 2012, 36:255259. 